\title{
Evaluation of phosphorylated insulin like growth factor binding protein-I and sonographically measured cervical length for prediction of preterm birth in threatened preterm labor: a clinical approach
}

\begin{abstract}
Background and Objectives: Measurement of cervical length using Transvaginal Sonography (TVS) is commonly used to identify those patients of threatened preterm labor who are likely to deliver. Biochemical markers in cervical secretions namely fetal fibronectin and Phosphorylated Insulin like Growth Factor Binding Protien-1 (phIGFBP-1) have also been used to improve predictability. This study evaluated bedside kit test for phIGFBP-1 and cervical length measurement by TVS, individually and in combination, for prediction of preterm birth in patients with threatened preterm labor.
\end{abstract}

Material and Method: A prospective observational study was conducted at a tertiary centre in India where women between $28+1$ and $36+6$ weeks period of gestation with threatened preterm labor were recruited and rapid bed-side test for phIGFBP-1 and TVS for measurement of cervical length were done. Patients were followed till delivery and data was collected and analysed.

Results: 468 patients completed the study. Statistical analysis of sensitivity, specificity, PPV and NPV showed that phIGFBP-1 was a better predictor of preterm birth compared to cervical length. There was very good correlation of phIGFBP-1 for prediction of delivery in the crucial period of next 7 days with a kappa of $0.833(0.780$ 0.886). Cervical length and phIGFBP-1 were shown to be independent predictors on multivariate regression analysis.

Conclusion: A negative result for phIGFBP-1 in cervico-vaginal secretions can predict quite accurately that threatened preterm labor will not progress to preterm birth. Cervical length measurement though reasonably good predictor, it does not add to the accuracy. In patients tested positive for phIGFBP-1, cervical length, being a time tested conventional method may be measured in selected patients and incorporated in the management algorithm in order to use the tests to guide management plan vis a vis utilizing the resources optimally.

Keywords: phigfbp-1, tvs, cervical length, preterm birth, threatened preterm labor, predictive tests
Volume 2 Issue 3 - 2017

\author{
Reva Tripathi, Shakun Tyagi, Preeti Yadav, \\ Meenoo S, Sarita Shah, Shalini Singh \\ Department of Obstetrics and Gynecology, Delhi University, \\ India
}

Correspondence: Preeti Yadav, Department of Obstetrics and Gynecology, Delhi University, India, Email yprity.04@gmail.com

Received: February 13, 2017 | Published: May 12, 2017
Abbreviations: FFN, fetal fibronectin; NPV, negative predictive value; TVS, transvaginal; ROC, receiver operating characteristic

\section{Introduction}

Preterm birth which accounts for $5-13 \%$ of total births, ${ }^{1}$ is an enigma in obstetrics as despite decades of research the precise etiology is not clear. Consequently, it is difficult to identify pregnancies which are likely to end in preterm birth. Among those presenting with threatened preterm labor, more than half do not deliver prematurely even without any treatment. ${ }^{2}$ Predicting the outcome in patients with threatened preterm labor is important as by treating those who are likely to deliver preterm, perinatal outcome can be improved. The prediction is easier in patients of threatened preterm labor where tests for fetal fibronectin (FFN) and Phosphorylated Insulin like Growth Factor Binding Protien-1(phIGFBP-1) (3,4 $^{3}$ and sonologically measured cervical length ${ }^{5,6}$ have been used with varying degrees of accuracy.
A study had been conducted earlier to compare bedside test for phIGFBP-1 and FFN in a cohort of patients with threatened preterm labor pains. ${ }^{7}$ Secondary analysis of the same data is now being presented where FFN test has been excluded as its specificity and negative predictive value (NPV) were much lower than for phIGFBP-1 test. Sonologically measured cervical length by transvaginal route (TVS) has been added to phIGFBP-1 in an attempt to evaluate the two tests as predictors of preterm birth and whether their combined use adds to the predictive accuracy. Retrospective analysis of the previous data was done with the aim to create a model that can be put into practical use in the clinical setting and to analyze if this could reduce the number of patients being hospitalized for treatment of threatened preterm labor.

\section{Material and methods}

A prospective observational study was conducted in a cohort of 
patients who presented with threatened preterm labor. The details of ethical clearance, patient selection and material used have already been published. ${ }^{7}$ In addition, TVS for cervical length measurement was done using following method. Patient was laid in lithotomic position after emptying the bladder. The transvaginal probe was placed in anterior fornix without undue pressure. Cervix was focused in sagittal plane such that the image occupies $75 \%$ of the screen and length of the end cervical canal was measured from internal so to external so in a straight line. Three measurements were taken and the shortest of the three was taken as final cervical length.

The tests used for the statistical analysis have also been detailed earlier. ${ }^{7}$ Additionally, for analysis in this study, receiver operating characteristic (ROC) curve was plotted and best cervical length cut off was calculated for prediction of overall preterm births i.e. births at less than 37 weeks gestational age and early preterm births i.e. birth at less than 34 weeks gestational age. Univariate and multivariate analysis was performed for the two predictors. For all statistical tests, a $p$ value less than 0.05 was taken to indicate a significant difference.

\section{Results}

Of 550 recruited patients, complete data of 468 patients was available for which analysis was done. Rest of the patients were excluded as they either lost to follow up or delivered elsewhere and final outcome data was not available.

No demographic characteristic was found to significantly affect gestational age at which delivery occurs. At the time of recruitment $5.77 \%(27)$ were between gestational age of 34 and 37 weeks. Among all the patients of threatened preterm labor, $41.88 \%(196)$ delivered Table I For phIGFBP-I test the sensitivity, specificity, PPV and NPV for predicting early preterm delivery were $94.38 \%, 78.10 \%, 50.30 \%$ and $98.34 \%$ respectively and the same parameters to predict delivery within next seven days of testing were $94 \%, 91.82 \%, 84.43 \%$ and $97.01 \%$ respectively

\begin{tabular}{|c|c|c|c|c|c|c|}
\hline & & & Sensitivity & Specificity & $\begin{array}{l}\text { Positive } \\
\text { predictive value }\end{array}$ & $\begin{array}{l}\text { Negative predictive } \\
\text { value }\end{array}$ \\
\hline \multirow{6}{*}{ Pogc $^{c}$ at Delivery } & \multirow{3}{*}{$<37$ weeks } & phIGFBP-I ${ }^{a}$ & $81.11 \%$ & $97.06 \%$ & $95.21 \%$ & $87.71 \%$ \\
\hline & & $C \times L^{b}$ & $71.94 \%$ & $81.98 \%$ & $74.21 \%$ & $80.22 \%$ \\
\hline & & $\mathrm{p}$ value & 0.18 & 0.008 & 0.001 & 0.17 \\
\hline & \multirow{3}{*}{$<34$ weeks } & phIGFBP- I $^{\mathrm{a}}$ & $94.38 \%$ & $78.10 \%$ & $50.30 \%$ & $98.34 \%$ \\
\hline & & $C x L^{b}$ & $79.77 \%$ & $68.60 \%$ & $37.37 \%$ & $93.52 \%$ \\
\hline & & $\mathrm{P}$ value & 0.005 & 0.22 & 0.11 & 0.31 \\
\hline \multirow{3}{*}{$\begin{array}{l}\text { Interval From } \\
\text { Testing to Delivery }\end{array}$} & \multirow{3}{*}{$<7$ days } & phIGFBP-I ${ }^{a}$ & $94.00 \%$ & $91.82 \%$ & $84.43 \%$ & $97.01 \%$ \\
\hline & & $C \times L^{b}$ & $80.67 \%$ & $78.30 \%$ & $63.68 \%$ & $89.57 \%$ \\
\hline & & $P$ value & 0.01 & 0.008 & 0.002 & 0.11 \\
\hline
\end{tabular}

${ }^{a}$ phIGFBP-I, Phosphorylated Insulin like Growth Factor Binding Protein-I

$\mathrm{BCxL}-$ Cervical length (cut off $<25 \mathrm{~mm}$ )

'POG, Period of Gestation

Cervical length was less than $25 \mathrm{~mm}$ in $40.6 \%$ of recruited patients. However, about a quarter of these delivered beyond 37 gestational weeks. Of the remaining three fourths who delivered preterm, almost half delivered before 34 weeks.

Table 1 compares the statistical parameters of phIGFBP-1 and cervical length as predictors of preterm birth, early preterm birth and delivery within next 7 days. It shows that phIGFBP-1 is the single best predictor.

Univariate logistic regression of cervical length of $25 \mathrm{~mm}$ showed odds ratio of $8.62(95 \% \mathrm{CI} 4.92-15.10)$ for predicting early preterm prior to 37 weeks and $19.01 \%(89)$ delivered before 34 gestational weeks.

The total number of patients who were phIGFBP-1 positive was $35.68 \%$ ( 167). Of these $95.21 \%$ delivered before 37 weeks, constituting $81.12 \%$ of total preterm births and $50.29 \%$ delivered before 34 weeks, constituting $94.38 \%$ of total early preterm births. Mean gestational age at delivery among patients positive for phIGFBP-1 was 32.9 $( \pm 2.25)$ weeks as compared to $37.9( \pm 1.52)$ weeks among phIGFBP-1 negative patients $(\mathrm{p}<0.001)$.

For phIGFBP-1 test the sensitivity, specificity, PPV and NPV for predicting early preterm delivery were $94.38 \%, 78.10 \%, 50.30 \%$ and $98.34 \%$ respectively and the same parameters to predict delivery within next seven days of testing were $94 \%, 91.82 \%, 84.43 \%$ and $97.01 \%$ respectively (Table 1 ).

The NPV of phIGFBP-1 for predicting delivery in next 48 hours was found to be $98.34 \%$ with a negative likelihood ratio of 0.06 . For prediction of delivery in next seven crucial days, phIGFBP-1 had best kappa of $0.833(0.780-0.886)$, suggestive of very good correlation between test and gestational age at delivery.

For evaluating cervical length, ROC curve was plotted Figure 1 and the best cervical length cut off for prediction of early preterm birth was observed to be $22.5 \mathrm{~mm}$ with sensitivity, specificity, PPV and NPV of $71.91 \%, 72.82 \%, 38.32 \%$ and $91.69 \%$. As shown in Table 2, these statistical parameters are not significantly different from those for cervical length of $25 \mathrm{~mm}$, which is well documented in literature and considered to be standard for clinical use. The cut off for predicting overall preterm birth was found to be $27.5 \mathrm{~mm}$. 
Table 2 Univariate analysis of cervical length and phIGFBP-I

\begin{tabular}{|c|c|c|c|}
\hline & P-value & OR* & $95 \% \mathrm{Cl}$ \\
\hline \multicolumn{4}{|c|}{ Preterm birth ( $<37$ Weeks) } \\
\hline phIGFBP-I & 0.0001 & $|4| .8 \mid$ & $64.42-312.19$ \\
\hline$C L<2.5$ & $0.000 \mathrm{I}$ & $\mathrm{II} .67$ & $7.52-18.10$ \\
\hline \multicolumn{4}{|c|}{ Early preterm birth ( $<34$ Weeks) } \\
\hline phIGFBP-I & 0.0001 & 59.91 & $23.53-152.53$ \\
\hline$C L<2.5$ & 0.0001 & 8.62 & $4.92-15.10$ \\
\hline
\end{tabular}

*OR-Odds Ratio
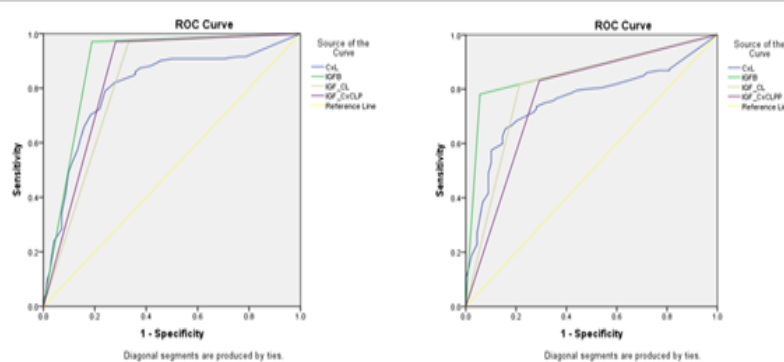

a. For delivery before 37 weeks

\begin{tabular}{|l|l|}
\hline Variable & AUC $(95 \% \mathrm{Cl})^{*}$ \\
\hline CXL & $0.805(0.763-0.847)$ \\
\hline phIGFBP-1 & $0.891(0.856-0.926)$ \\
\hline
\end{tabular}

b. For delivery before 34 weeks

\begin{tabular}{|l|l|}
\hline Variable & AUC $(95 \% \mathrm{Cl})^{*}$ \\
\hline CXL & $0.756(0.707-0.805)$ \\
\hline phIGFBP-1 & $0.862(0.824-0.901)$ \\
\hline
\end{tabular}

*AUC - Area Under Curve, $\mathrm{Cl}$ - Confidence Interval

Figure I For evaluating cervical length, ROC curve was plotted.

As shown in Table 3, when both tests were used in combination the specificity and PPV for prediction of preterm birth prior to 37 weeks were significantly increased as compared to that of cervical length alone. However, no significant difference was observed

Table 3 Comparison of phIGFBP-I and cervical length, individually and in combination for prediction of preterm birth $(<37$ weeks) and early preterm birth (<34 weeks)

\begin{tabular}{|c|c|c|c|c|c|}
\hline \multicolumn{2}{|c|}{ POGc at delivery } & \multirow{2}{*}{$\begin{array}{l}\text { Sensitivity } \\
81.11 \%\end{array}$} & \multirow{2}{*}{$\begin{array}{l}\text { Specificity } \\
97.06 \%\end{array}$} & \multirow{2}{*}{$\begin{array}{l}\text { Positive predictive value } \\
95.21 \%\end{array}$} & \multirow{2}{*}{$\begin{array}{l}\text { Negative predictive value } \\
87.71 \%\end{array}$} \\
\hline \multirow{6}{*}{$<37$ week } & phIGFBP- $\left.\right|^{a}$ & & & & \\
\hline & phlGFBP-I + CxL & $66.84 \%$ & $97.06 \%$ & $97.24 \%$ & $80.24 \%$ \\
\hline & $P$ value & 0.04 & 1 & 0.89 & 0.18 \\
\hline & $C x L^{b}$ & $71.94 \%$ & $81.98 \%$ & $74.21 \%$ & $80.22 \%$ \\
\hline & phIGFBP-I + CxL & $66.84 \%$ & $97.06 \%$ & $97.24 \%$ & $80.24 \%$ \\
\hline & $P$ value & 0.56 & 0.0008 & 0.0002 & I \\
\hline \multirow{6}{*}{$<34$ week } & phIGFBP- $I^{a}$ & $94.38 \%$ & $78.10 \%$ & $50.30 \%$ & $98.34 \%$ \\
\hline & phIGFBP-I + CxL & $78.65 \%$ & $81.79 \%$ & $50.36 \%$ & $94.22 \%$ \\
\hline & $P$ value & 0.003 & 0.58 & 0.96 & 0.56 \\
\hline & $37.37 \%$ & $79.77 \%$ & $68.60 \%$ & $37.37 \%$ & $93.52 \%$ \\
\hline & phIGFBP-I + CxL & $78.65 \%$ & $81.79 \%$ & $50.36 \%$ & $94.22 \%$ \\
\hline & $P$ value & 0.8 & 0.08 & 0.07 & I \\
\hline
\end{tabular}

aphIGFBP-I, Phosphorylated Insulin like Growth Factor Binding Protein- I.

${ }^{\mathrm{b}} \mathrm{CxL}$, Cervical length (cut off $<25 \mathrm{~mm}$ ).

cPOG, Period of Gestation.

Citation: Tripathi R, Tyagi S, Yadav P, et al. Evaluation of phosphorylated insulin like growth factor binding protein-I and sonographically measured cervical length for prediction of preterm birth in threatened preterm labor: a clinical approach. Int J Pregn \& Chi Birth. 20I7;2(3):8I-86.

DOI: I0.15406/ipcb.2017.02.00024 
Meta-analysis by Sotiriadis et al. ${ }^{12}$ concluded that short cervical length can be used to help scrutinize symptomatic patients for further treatment. They estimated negative predictive values of $94.8 \%, 96.3 \%$ and $95.8 \%$ at cervical length of $15 \mathrm{~mm}, 20 \mathrm{~mm}$ and $25 \mathrm{~mm}$ respectively. These variable cut offs were calculated in different studies and can be attributed to heterogeneous population, variable gestational age at testing and also to inter-observer differences. After being studied in many large studies, $25 \mathrm{~mm}$ has been defined as standard cut off value for high risk asymptomatic patients ${ }^{13,14}$ and many studies calculated it to be the cut off in symptomatic patients as well.15 In this study, ROC curve was plotted and $22.5 \mathrm{~mm}$ and $27.5 \mathrm{~mm}$ were recorded as best cut off for predicting preterm birth before 34weeks and 37 weeks respectively. However the statistical parameters for $25 \mathrm{~mm}$ and $22.5 \mathrm{~mm}$ were not significantly different. Hence, to maintain uniformity with literature, cervical length cut off of $25 \mathrm{~mm}$ was considered for statistical comparisons.

Only recently, few studies evaluated and compared phIGFBP-1 and cervical length in symptomatic patients. These were conducted with limited sample size. The first such study was conducted in patients who were asymptomatic but at high risk due to previous events by Bittar et al. ${ }^{16}$ showing improved prediction by sequential combined use of cervical length in mid trimester and phIGFBP-1 detection in early third trimester, predicting $91.7 \%$ of early preterm births and $80 \%$ of total preterm births. They concluded that two tests are independent, as shown by multivariate analysis.

Paternoster et al. ${ }^{17}$ assessed both parameters in 201 patients with threatened preterm labor and determined cervical length cut off to be $26 \mathrm{~mm}$ with sensitivity, specificity, PPV and NPV of $86.4 \%, 71.9 \%$, $34.5 \%$ and $96.8 \%$ respectively and having odds ratio of 16.18 (4.4658.66 ). These parameters for phIGFBP- 1 were $52.9 \%, 89.2 \%, 48.7 \%$ and $90.8 \%$ respectively with odds ratio of $9.29(4.05-21.3)$. They also found the two tests to be independent of each other. The combination was shown to be better for predicting preterm birth than either test alone with a greater specificity $(96.1 \%)$ and positive predictive value $(64.3 \%)$ but the statistical comparison was not done. In this study similar statistical parameters for cervical length were observed with better parameters for phIGFBP-1.

Another study of 246 symptomatic patients done by Rahkonen et $a .^{18}$ concluded that for prediction of early preterm delivery, combination of phIGFBP-1 and cervical length (using $25 \mathrm{~mm}$ cut off) had lower sensitivity but higher positive predictive value than either test alone. The high NPV of phIGFBP-1(97.6\%) was found to be comparable to that of cervical length $(97.4 \%)$ and hence concluded that the former is an alternative to the latter as it is cheaper and does not require great expertise in performing the test. But the study had preterm birth rate of only $4.1 \%$, which is much lesser than usually observed.

In this study it was observed that on combining the two tests, sensitivity fell significantly as compared to phIGFBP-1 test alone. Table 3 Similarly NPV also was less but the difference was not statistically significant. The sensitivity and NPV of combination was similar to that of cervical length alone. In contrast to this, the combination had better specificity and PPV as compared to cervical length alone. However the difference was statistically significant only in predicting overall preterm birth and not for early preterm birth. Specificity and PPV remained statistically similar both for combination and for phIGFBP-1 testing alone. These results indicate the increased predictability on combining phIGFBP-1 with cervical length.

Brik et al. ${ }^{19}$ studied the results of cervical swab phIGFBP-1 test and cervical length in 276 symptomatic women. Cut off for cervical length was observed to be $20.5 \mathrm{~mm}$. It was concluded that phIGFBP- 1 test is a reasonable predictive test for preterm birth (sensitivity, specificity, PPV and NPV of $59 \%, 66 \%, 23.4 \%$ and $88.6 \%$ respectively) but did not improve the predictive value of cervical length considering admission to delivery interval.

Danti et al. ${ }^{20}$ proposed that phIGFBP-1 testing is needed only among patients with cervical length between 20 and $30 \mathrm{~mm}$ when the specificity is low, though this study had only 60 patients. These variable results of combination of cervical length and phIGFBP-1 suggest that both the tests should only be done in selected patients in order to utilize resources efficiently.

It is well known that for a test to be used for screening it should have both high sensitivity and negative predictive value. Testing for phIGFBP-1 fulfilled these criteria, more so for delivery in the crucial period of next seven days after testing (sensitivity $94 \%$ and NPV $97.01 \%$ ). The comparison of statistical parameters for both tests clearly showed that test for phIGFBP-1 is a better test. The odds ratio of phIGFBP-1 test was highly significant for predicting preterm births before 34 gestational weeks whereas, $25 \mathrm{~mm}$ cut off of cervical length was found to be only moderately significant for prediction of early preterm birth as suggested by odds ratio of 8.62(4.92-15.10).

Since these two tests are independent, their combination can be made use of to improve the predictive accuracy in selected patients though, which one should be done first may be questioned. The statistical parameters shown in table 3 imply that phIGFBP-1 should be done first as addition of cervical length does not confer further benefit. The additional advantage of bedside test for phIGFBP-1 is that it is also an objective, easy to perform test which does not need expertise and expensive equipment. Hence it can also be done at smaller centers by paramedics. In contrast, TVS for cervical length needs expertise and availability of an expensive machine. Hence we suggest phIGFBP-1 to be done first and TVS for cervical length to be performed in only those who test positive of phIGFBP-1.

As phIGFBP-1 has greater negative predictive value, patients with negative test can be discharged. In this study $64.31 \%$ (301) admissions of patients with threatened preterm labor pains could have been avoided. Among these patients only $1.66 \%(5)$ had early preterm birth none of which could have been predicted by cervical length alone. Specificity of the combination is more than that of phIGFBP-1 alone $(81.99 \%$ vs $78.1 \%)$. Those with both the tests positive should be admitted and started on treatment as is suggested by the fact that $87.64 \%$ of those who delivered before 34 weeks fall in this group.

If the patients with positive phIGFBP-1 test result but cervical length more than $25 \mathrm{~mm}$ had been admitted, observed and treated only if pain persisted, treatment in many could have been safely avoided. There were 23 patients falling in this group who tested positive for phIGFBP-1 but had cervical length above the cutoff of $25 \mathrm{~mm}$. Among these, 17 patients delivered after 34 gestational weeks in whom treatment could have been avoided safely, whereas six patients had early preterm birth. All these cases require admission and observation but treatment needs to be started only in certain cases of continuing symptoms/signs. The data has been translated into the following 
algorithm Figure 2 which we suggest has practical utility without compromising maternal or perinatal safe try.

Figure 2 Suggested algorithms for management of patients with threatened preterm labor. The strength of the study was the size of the cohort studied. However, there were few limitations as well. Despite being a subjective test where inter observer variation could be present, TVS for measuring cervical length was not done by the same person. Also there were around $15 \%$ of patients who were lost to follow up. The study presents a very basic assessment of decreased cost and not a scientifically calculated cost-benefit ratio analysis. Another drawback of the approach which has been suggested here is the number of the patients which would be missed. By this approach $1.06 \%$ of total patients would deliver before 34 weeks, where treatment has not been instituted. The proposed algorithm needs to be validated by larger studies, where patients who were not given any intervention could be followed up telephonically or by paramedics conducting home visits.

To conclude, bedside phIGFBP-1 test appears to be a better test to rule out the risk of preterm birth in patients with threatened preterm labor in comparison to evaluation of cervical length. Cervical length measured by TVS has been the time tested predictor and can be done in selected patients. By following this approach we can limit the number of hospitalizations. Additionally, of those who are admitted, treatment could be avoided in many patients. This would result in saving on resources by avoiding unnecessary treatment and minimizing fetomaternal exposure to drugs. Additionally, transfer of patients to higher center can be avoided if risk of preterm birth is ruled out at smaller centers by an inexpensive and objective test with a high degree of accuracy.

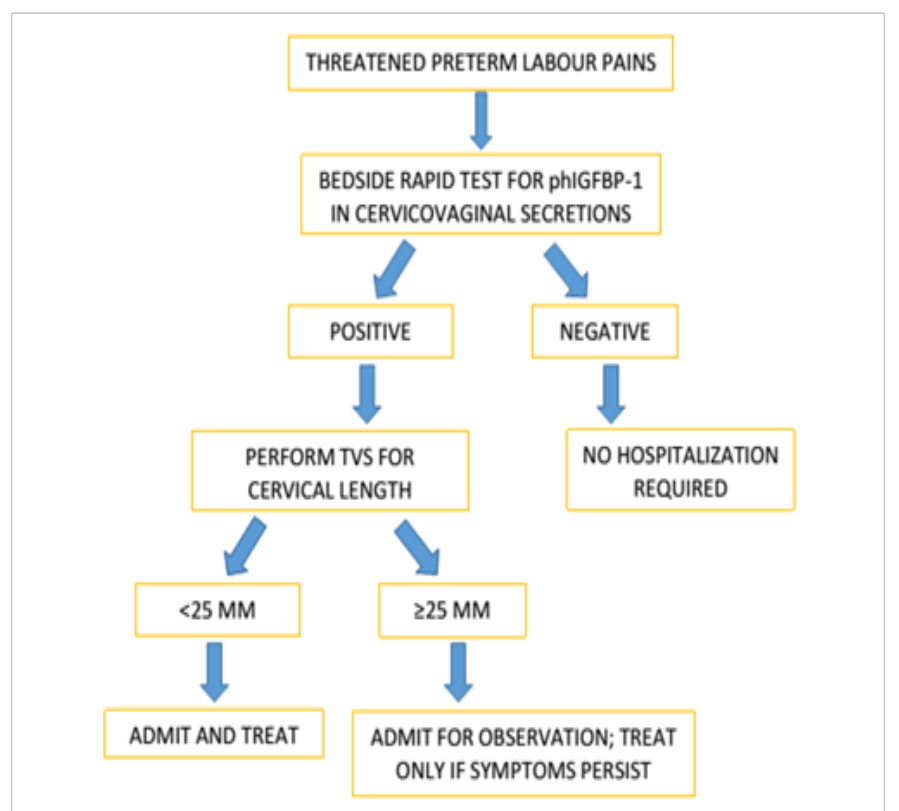

Figure 2 Suggested algorithms for management of patients with threatened preterm labor.

\section{Acknowledgements}

None.

\section{Conflict of interest}

Author declares that there is no conflict of interest.

\section{References}

1. Goldenberg RL, Culhane JF, Iams JD, et al. Epidemiology and causes of preterm birth. Lancet. 2008;371(9606):75-84.

2. Kenyon SL, Taylor DJ, Tarnow-Mordi W. Broad spectrum antibiotics for spontaneous preterm labor: The ORACLE II randomized trial. Lancet. 2001;375(9261):989-994.

3. Rutanen EM. Insulin-like growth factor in obstetrics. Curr Opin Obstet Gynaecol. 2000;12(3):163-168.

4. Kekki M, Kurki T, Karkkainen T, et al. Insulin-like growth factor-binding protein-1 in cervical secretions as a predictor of preterm delivery. Acta Obstet Gynecol Scand. 2001;80(6):546-451.

5. Andersen HF, Nugent CE, Wanty SD, et al. Prediction of risk for preterm delivery by ultrasonographic measurement of cervical length. $\mathrm{Am}$ J Obstet Gynecol. 1990;163(3):859-867.

6. Iams JD, Goldenberg RL, Meis PJ, et al. The length of the cervix and the risk of spontaneous premature delivery. National Institute of Child Health and Human Development Maternal Fetal Medicine Unit Network. N Engl J Med. 1996;334(9):567-572.

7. Tripathi R, Tyagi S, Mala YM, et al. Comparison of rapid bedside tests for phosphorylated insulin-like growth factor-binding protein 1 and fetal fibronectin to predict preterm birth. Int J Gynecol Obstet. 2016;135(1): 47-50.

8. Lembet A, Eroglu D, Ergin T, et al. New rapid bedside test to predict preterm delivery: phosphorylated insulin-like binding protein-1 in cervical secretion. Acta Obstet Gynecol Scand. 2002;81(80):706-712.

9. Kwek K, Khi C, Ting HS, et al. Evaluation of a bedside test for phosphorylated insulin-like growth factor binding protein-1 in preterm labor. Ann Acad Med Singapore. 2004;33(6):780-783.

10. Tanir HM, Sener T, Yildiz Z. Cervical phosphorylated insulin-like growth factor binding protein-1 for the prediction of preterm delivery in symptomatic cases with intact membranes. J Obstet Gynaecol Res. 2009;35(1):66-72.

11. Akercan F, Kazandi M, Sendag F, et al. Value of cervical phosphorylated insulin like growth binding protein-1 in prediction of preterm labor. $J$ Reprod Med. 2004;49(5):368-372.

12. Sotiriadis A, Papatheodorou S, Kavvadias A, et al. Transvaginal cervical length measurement for prediction of preterm birth in women with threatened preterm labor: a meta-analysis. Ultrasound Obstet Gynecol. 2010;35(1):54-64.

13. Guzman ER, Walters C, Ananth CV, et al. A comparison sonographic cervical parameters in predicting spontaneous preterm birth in high-risk singleton gestations. Ultrasound Obstet Gynecol. 2001;18(3):204-210.

14. Iams JD, Paraskos J, Landon MB, et al. Cervical sonography in preterm labor. Obstet Gynecol. 1994;84(1):40-46.

15. Mella MT. Prediction of preterm birth: cervical sonography. Semin Perinatol. 2009;33(5):317-324.

16. Bittar RE, Da Fonesca EB, De Carvalho MH, et al. Predicting preterm delivery in asymptomatic patients with prior preterm delivery by measurement of cervical length and phosphorylated insulin-like growth factor binding protein-1. Ultrasound Obstet Gynecol. 2007;29(5):562-567.

17. Paternoster D, Riboni F, Vitulo A, et al. Phosphorylated insulin-like growth factor binding protein-1 in cervical secretions and sonographic cervical length in prediction of spontaneous preterm delivery. Ultrasound Obstet Gynecol. 2009;34(4):437-440.

18. Rahkonen L, Unkila Kallio L, Nuutila M, et al. Cervical length measurement and cervical phosphorylated insulin-like growth factor binding protient-1 testing in prediction of preterm birth in patients reporting uterine contractions. Acta Obstet Gynecol Scand. 2009;88(8):901-908. 
19. Brik M, Hernandez AI, Pedraz CC, et al. Phosphorylated insulin-like growth factor binding protein-1 and cervical measurement in women women with threatening preterm birth. Acta Obstet Gynecol Scand. 2010;89(2):268-274.
20. Danti L, Perfumo F, Lojocono A, et al. The combination of short cervical length and phIGFBP-1 in the prediction of preterm delivery in symptomatic women. J Matern Fetal Neonatal Med. 2011;24(10):1262-1266. 